\title{
Power and Sociability
}

\author{
Joachim I. Krueger ${ }^{1}$ \\ (joachim_krueger@brown.edu) \\ David J. Grüning² \\ (david.gruening@psychologie.uni-heidelberg.de) \\ Tanushri Sundar ${ }^{1}$ \\ (tanushri_sundar@alumni.brown.edu) \\ 1: Brown University \\ 2: Heidelberg University
}

Krueger, J. I., Grüning, D. J., \& Sundar, T. (in press). Power and sociability. In J. P. Forgas, W. D. Crano, \& K. Fiedler (eds.), The psychology of sociability. The Sydney Symposium on Social Psychology, 23. Taylor \& Francis. 


\begin{abstract}
Social life unfolds with tension between power and sociability. As both, the need of power and the need of sociability, are crucial to interpersonal transactions, the person faces a dilemma. The satisfaction of one need limits the satisfaction of the other. We approach this dilemma by first reviewing two seemingly contrary biases in social perception: self-enhancement and social projection, which are respectively associated with power and sociability needs. We then discuss the ultimatum game, which puts the mandates of power and sociability into direct conflict. Data suggest that observers are sensitive to both material and social interests when judging players' character. We then introduce a general power game, describe it with the theory of moves, and review observer-judgment data. We conclude with an exploration of how individuals might incorporate reputational concerns into their social decision-making and speculate about how the power-sociability dilemma can be transcended if it cannot be solved.
\end{abstract}




\section{Introduction}

A number of porcupines huddled together for warmth on a cold day in winter; but, as they began to prick one another with their quills, they were obliged to disperse. However the cold drove them together again, when just the same thing happened. . . In the same way the need of society drives the human porcupines together, only to be mutually repelled by the many prickly and disagreeable qualities of their nature.

-Arthur Schopenhauer (1851/1964, p. 226)

The concept of sociability pervades the mission, the methods, and the self-construal of social psychology (Allport, 1924). Humans are a social species. For sociologists, this is axiomatic (Gumplowicz, 1885/2017; Tönnies, 1887/2012). Many biologists agree (Wilson, 2004), classing humans with bees or ants, which are social animals in that individual organisms cooperate with one another to achieve collective aims. But bees or ants are not sociable.i For humans, the concept of sociability suggests a need to be in the presence of and engaging with other humans, and it entails the idea that this need better be satisfied (Simmel, 1910/1949). Sociability is associated with affiliation, inclusion, love, conformity, and cooperation (see von Hippel \& Smith, this volume). Desirable as it is, sociability can be hard to attain. The characters in the works of Sartre, Strindberg, and Bergman fail at this task. They are social, but they are not sociable.

When social psychologists refer to the human being as a social animal, they often look to Aristotle. The Macedonian sage regarded humans as "political animals," creatures placed in hierarchically organized societies. If humans are free and live in a polis (or 'republic'), they can participate in the processes of debate, persuasion, influence, deception, and expulsion (Rosler, 2013). In this context, the psychology of sociability taps into a wide range of capacities associat- 
ed with social intelligence, social perception, and social behavior. The pleasure of being in one another's company is part of a larger social ecology.

Social psychology has not done well owning and developing the concept of sociability. The work has been largely left to the trait school of personality psychology (Cheek \& Buss, 1981). The trait model casts sociability as a facet of extraversion (Lucas et al., 2000), and perhaps the most important one (McCrae \& Costa, 1987). One might wonder what would be left of extraversion if sociability were excised. Zorba the Greek (Kazantzakis, 1946/2016) might be dancing alone on a Cretan beach, hollering jubilantly. But what kind of extraversion would that be? Dancing the Hasapiko with the "Boss," however, and teaching him the joys of dancing, Zorba displays extraversion in its prototypically sociable form.

The trait approach, valuable as it is, has limitations. Being a paradigm of measurement and prediction, trait psychology has little to say about various kinds of mentalizing that characterize and guide social behavior. This is where a social psychology of sociability can be useful. In this chapter, we take up Aristotle's concern with the political dimension of social life. We assume that the social world is not benign, no matter how fervently we want it to be. Status and power hierarchies are ubiquitous (Anderson et al., 2015), and they are often unstable; they are constantly challenged, defended, and re-negotiated (Sapolsky, 2017). Some people try to cope with this uncertainty by following Machiavelli. Prioritizing power, they might fake sociability instead of enjoying it (Christie \& Geis, 1970). Others find enlightenment in the writings of the young Frederick II of Prussia, who, before becoming an autocratic king, sought to refute Machiavelli in his "Anti-Machiavel," declaring the Florentine's doctrine "monstrous" (Lifschitz, 2021). 
Irrespective of personality and politics, most people experience some conflict between self-assertion and affiliation, that is, between power and sociability (see Baumeister and Maranges; and Kruglanski \& Ellenberg, this volume). We take this to be the fundamental social dilemma: how can an individual get ahead in a group without sacrificing supportive, respectful, or loving relations with other group members? If there were no conflict, one might even have it both ways and be loved by those whom one has subdued. Such harmony between power and sociability is elusive. In Book IX of the Iliad, Achilles tells Odysseus what his mother, the goddess Thetis, had told him: he could either join the fight against the Trojans, die a hero, and his "glory will live forever," or he could return to his ancestral Thessaly, enjoy a full and peaceful life, but his "glory will die" (Mitchell, 2011, p. 440). Moved by reputational greed and a thirst for vengeance, Achilles sacrificed sociability — and life. The rest is history — or legend.

To explore the power-sociability dilemma, we take a social-cognitive and game-theoretical approach. In the first section of this chapter, we review two elements of social perception, namely, self-enhancement and social projection, which are associated with power and sociability, respectively. In the second section, we review the social perception of players' competence and morality in the ultimatum game with a view to power differentials. In the third section, we introduce a general power game, analyze it in light of the theory of moves (Brams, 1994, 2011), and present social-perception data, again with a view to competence and morality. In the final section, we ask how individuals might allow perceived social perception, that is, reflected appraisals, to enter into their decision-making within dilemmas. We close with a reflection on personal freedom, a concept that transcends the basic dilemma. 


\section{Social Perception and the Basic Dilemma}

The perception of others and the perception of the self are entangled with one another (Alicke et al., 2005). People do not have impartial bird's-eye views of themselves or others, much as they might try. Comparisons spontaneously arise, creating a push and pull of perceived similarity and difference (Suls \& Wheeler, 2000). Social-cognitive theory has long framed any evidence of comparative effects as evidence of bias. This implies that noncomparative judgment is both desirable and possible (Krueger et al., 2013). The assumption that social perceivers are less than rational has led to a flood of claims about contradictory biases such as false consensus and false uniqueness or over- and underconfidence (Krueger \& Funder, 2004). Research on selfenhancement (or overconfidence) and social projection (a.k.a., "false consensus") is of interest here because these biases respectively tap into motives of power (e.g., self-assertion, competition, dominance, and individuation) and motives of sociability (e.g., affiliation, cooperation, and collectivization) (see also Fiedler \& Hütter, this volume).

Self-enhancement is typically taken to serve the motive of feeling good about oneself (Alicke \& Govorun, 2005; Brown, 2012). The better-than-average variant of this bias captures a positive differentiation of the self from others (Krueger et al., 2017). Self-enhancement thereby becomes conflated with other-diminishment (Heck \& Krueger, 2015). To say that one person is better than another person is to assert oneself, and others tend to object ("You think you're better than me?"). Observers may judge self-enhancers as more competent than others, but only if their claims to superiority are backed up by evidence. Regardless of whether these claims are correct or not, perceivers rate self-enhancers as less moral than others (Heck \& Krueger, 2016). Broad- 
casting self-enhancing claims carries the risk of alienating potential social partners and is thus a threat to affiliation and sociability.

Social projection is seldom studied through a motivational lens. Most research focuses on the informational value of self-referent information for predictions about others under conditions of uncertainty (Krueger, 2007; Krueger \& Grüning, 2021; Thielmann et al., 2018). This approach construes social projection as an accuracy-enhancing prediction heuristic. Yet, motivational accounts have always been considered. In their seminal work on the false consensus effect, Ross, Greene, and House (1977) noted that people may wish to assume consensus (i.e., similarity) with others because similarity implies social connectedness and the normalcy of the self. Heck and Krueger (2020) provided direct evidence for this idea, showing that individuals who, to their own surprise, failed at a reasoning task were particularly likely to project this outcome to others.

In short, self-enhancement as a claim of superiority is related to the concept of power and overconfidence (Larrick et al., 2007; Moore, 2020). Highly confident individuals are most likely to enter competitions for material gain and vie for leadership positions (Kamas \& Preston, 2012). The many who fail turn out to be overconfident after the fact, a judgment that amounts to an outcome bias (Baron \& Hershey, 1988; Krueger, et al., 2020). In contrast, social projection is associated with sociability and affiliation as it is well established that perceived similarity predicts liking (Byrne, 1961; Clement \& Krueger, 1998).

In its simplest form, the power-sociability dilemma suggests a hydraulic system in which self-enhancement and social projection are perfectly negatively correlated. As one bias increases, the other must decrease. Indeed, early theorists equated self-enhancement with the bias of false uniqueness, that is, the logical opposite of false consensus. But it soon became clear that this 
cannot be so (Krueger, 2000). If the distribution of scores is negatively skewed, that is, if there are few spectacular failures, most individuals are better than average, and seeing themselves as such is neither an error nor does it reveal a false sense of uniqueness. Even symmetrical distributions do not entail a necessary mapping of self-enhancement on false uniqueness, as self-effacers would also be considered victims of the false-uniqueness fallacy.

Although there are constraints on the joint emergence of self-enhancement and social projection, the two biases can — and often do-co-exist. One statistical consideration is that selfenhancement is typically conceptualized and measured as a difference in mean level, whereas social projection takes the form of a correlation between self- and other judgments over items (traits, behaviors, preferences, etc.). Barring ceiling or floor effects, individuals can construe themselves both as better than others (with more favorable judgments on most items) and as similar to them (with a positive covariation between self and other judgments; Krueger, 2002). We estimated the statistical relationship between self-enhancement and social projection in two data sets. Each data set comprised judgments from about 200 respondents, which we separated into 10 equally large subsamples, computed self-enhancement as the difference between average selfratings and average ratings of the average other, and social projection as the correlation between self-ratings and other ratings over respondents. In one data set, raised in a lecture course in the spring of 2021, respondents rated their own and others' happiness. In the other data set, respondents had to rate own and others' contentedness (Heck \& Krueger, 2015). The two correlations were positive though small $(\mathrm{r}=.29$ and .14$)$. With a more rigorous bootstrapping procedure involving 1,000 re-samples from each data set, the mean correlations between the two biases were lower, that is, -.02 and -.24 , but still not wildly negative. 
In social dilemmas as well, self-enhancement and social projection can co-occur. In the volunteer's dilemma, for example, most respondents claim they are more likely than others to make a prosocial sacrifice, while their estimates of the likelihood of others' volunteering are positively correlated (over scenarios and over respondents) with their own decisions (Krueger et al., 2016). Indeed, social projection can facilitate cooperation (Krueger, 2013). In a prisoner's dilemma, players who project at the limit, that is, players who believe others choose the same strategy as they themselves choose, will cooperate rather than defect because mutual cooperation is payoff-dominant, that is, better for everyone (Krueger et al., 2012). Such findings are reminiscent of Codol's (1975) classic demonstration that most people think they are superior to others in that they more faithfully follow group norms. Taken together, these findings suggest that the dual tendencies to enhance the self and to project it not only fuel the fundamental social dilemma but also create room for a positive balance. We now turn to two experimental games to explore strategies people use to balance the needs of power and sociability.

\section{Social Perception in the Ultimatum Game}

The most powerful weapon in chess is to have the next move.

—David Bronstein

Once introduced by Güth, Schmittberger, and Schwarze (1982), the ultimatum game has become a Petri dish for hypotheses, experimental data, and inferences about human nature and strategic behavior. The game itself is simple. One player proposes a proportional split of a small sum of money to a responder. If this responder accepts the offer, both players receive the proposed share of the money. If the responder rejects the offer, presumably because it is insultingly low, neither player receives anything (see also Forgas, this volume). 
Most research has focused on responders' decision-making. Once offers fall below 30\% of the purse, many prefer to receive nothing (Camerer, 2003). Why? Theories and speculations abound. Classic game theory, as Güth himself anticipated, is at a loss because a rational player prefers any amount of money to no money at all. When the responder rejects an offer, other values, emotions, or motives, such as righteous anger and the will to punish, must have come into play (Gabay et al., 2014; Xiao \& Houser, 2005). What we see is the wrath of the responder. Social game theory (Krueger et al., 2020) adds a formerly neglected element of social perception to the puzzle. The theory states that players know their behavior is meaningful in the eyes of others (and thus their own eyes). Transactional behavior signals real and claimed power, and it provokes moral evaluation. The theory assumes that humans care about how their behavior reflects on them (Wu et al., 2016). This is not an entirely new idea. David Hume (1740/1978) based his theory of motivation on it.

Here we report findings from an informal study conducted as part of a class project to highlight how observers evaluate decisions in the ultimatum game along the dimensions of competence and morality (see also Tham et al., 2021). Participants $(\mathrm{N}=198)$ rated a proposer, an accepting responder, or a rejecting responder. All participants read about offers that were fair ( $\$ 5$ out of $\$ 10)$, a little selfish $(\$ 4)$, or greedy $(\$ 1)$. On 7-point scales, they rated both players on the adjectives competent, intelligent, and rational, as well as on the adjectives moral, benevolent, and principled. In each condition, ratings were reliable $(\alpha>.81$ for competence and $\alpha>.78$ for morality). Adjective ratings were therefore averaged to form composite scores of competence and morality. Figure 11.1 shows the mean ratings for the three experimental conditions. In what 
follows, we report descriptive statistics and effect sizes. Unless otherwise noted, these effects are statistically significant at the conventional .05 level.

Judgments of competence and morality were positively correlated with each other in each condition (mean $r=.52$; after Fisher's r-Z-r transformation). Participants evaluated the proposer (morality: $\eta^{2}=.60$; competence: $\eta^{2}=.27$ ) and the accepting responder (morality: $\eta^{2}=.12$; competence: $\eta^{2}=.26$ ) positively to the extent that offers were generous. They evaluated a rejector positively to the extent that offers were low (morality: $\eta^{2}=.20$; competence: $\eta^{2}=.39$ ). This latter finding may seem surprising because it indicates rejectors received more credit for those judgments that are easier to make.

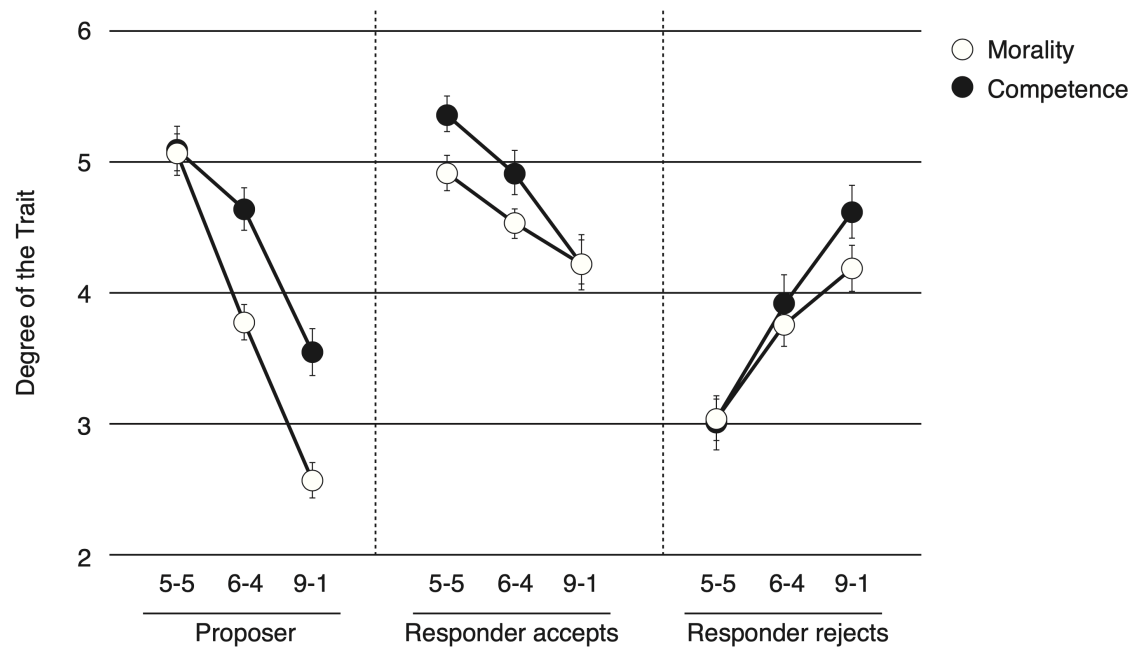

Figure 1. Means (and error bars) for competence and morality judgments in the 3 (Proposer versus Responder accepts versus Responder rejects) $\times 3(5-5$ versus 6-4 versus 9-1) $\times 2$ (Morality and Competence) design.

Knowing that observers prefer to see a fair exchange, ultimatum gamers can anticipate how they will be viewed given their choices. Proposers concerned about their moral reputation may bias their offers toward generosity, and responders might reject material offers they could 
otherwise obtain. Such reputational concerns might help explain the standard finding that the outcomes of ultimatum games depart from strict game-theoretic rationality.

Note that the ultimatum game contains a sequential power play. Proposers have the right of the first move and thus the power to frame the deal. They have an opportunity to do better-if only by a little — than responders, who will likely accept a 6:4 split. Yet, the proposers' power is fleeting. Once exercised, it is gone. Responders have the power of the last word, being able to claim reputational compensation by rejecting a bad deal. A mildly unattractive deal may be a bitter pill because it leaves a material disadvantage without much reputational compensation. The opportunity to offer such a deal could leave the proposer with a small power advantage.

Our participants attributed a small $(\mathrm{d}=.19)$ and nonsignificant power advantage to the proposer $(M=5.20$ versus $M=4.75$ for the responder $)$. When asked which role they themselves would prefer to play, a slight (and marginally significant) majority of 56\% opted for the proposer role. Individual role preferences predicted the differences in the power judgments for the two roles $(\mathrm{r}=.44)$. As power is distributed in the ultimatum game, choosing a role is hard. Choosers must determine which type of power they prefer.

The differences in the results obtained in the three conditions provide further insights. When participants had observed the decisions made by a proposer $(d=.39)$ or had seen an accepting responder $(\mathrm{d}=.31)$, they considered the proposer to be more powerful. In contrast, they considered the responder more powerful when they had seen offers rejected $(d=.20$, marginally significant; see Figure 11.2 for all means). 


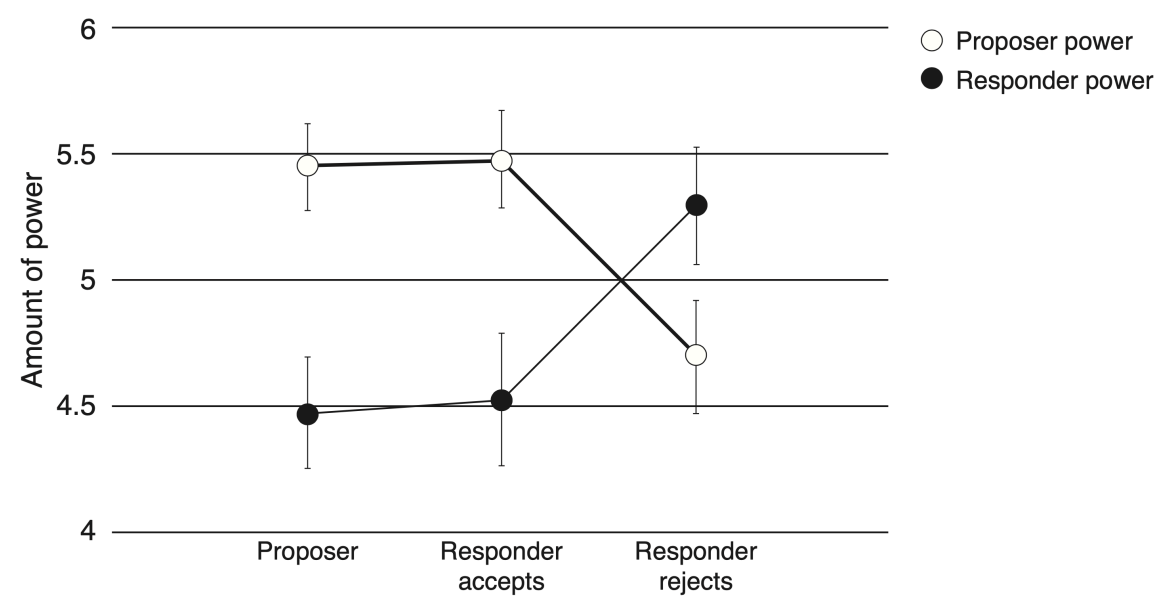

Figure 2. Means (and standard errors) of power judgments for a proposer (white) and a responder (black) in the three between-subjects conditions (Proposer versus Responder accepts versus Responder rejects).

Participants also rated themselves on the same trait adjectives, allowing us to see self-enhancement and social projection. In each condition, they rated themselves as more moral $\left(M_{\text {self }}=\right.$ 5.26 versus $\left.M_{\text {player }}=3.91, d=1.10\right)$ and as more competent $\left(M_{\text {self }}=5.42\right.$ versus $M_{\text {player }}=4.26, d$ $=.82)$ than other players. Social projection was captured by the correlations-across respondents - between self-ratings and ratings of others (mean $r=.26$ ). The degree of social projection showed little variation over conditions or between the dimensions of competence and morality. Again, self-enhancement and social projection (perceived similarity) can, to a degree, go together.

The ultimatum game shows off the complexity of the power-sociability dilemma. Whereas the proposer is a gambler who tries to find a balance between a comparative material advantage and social acceptance, the receiver is left to using power as a costly signal of own strength or virtue. The two are in conflict. It takes more spite to reject a mildly unfair offer, but the moral credit is greater for rejecting highly unfair offers. The wrath of Achilles at Agamemnon's over- 
bearing claim on the captured Princess Briseis is a Homeric example of determination in defeat without the benefit of moral credit. Achilles, it seems, won the admiration of the Greeks because he let them down, not in spite of letting them down. Heroes are rarely remembered for their high morality.

\section{A General Power Game}

The fundamental concept in social science is Power, in the same sense in which Energy is the fundamental concept in physics.

The ultimatum game teaches us that power is rarely a one-way street. Often, all interactants have access to particular power moves. The data suggest that moral and affiliative concerns can be relevant input to a player's choice. Many games described by game theory contain a conflict between doing well and getting along well, that is, the conflict between power and sociability. We now describe a simple and generic power game, where conflict arises from players' misaligned preferences. Figure 11.3 shows the game in matrix form.

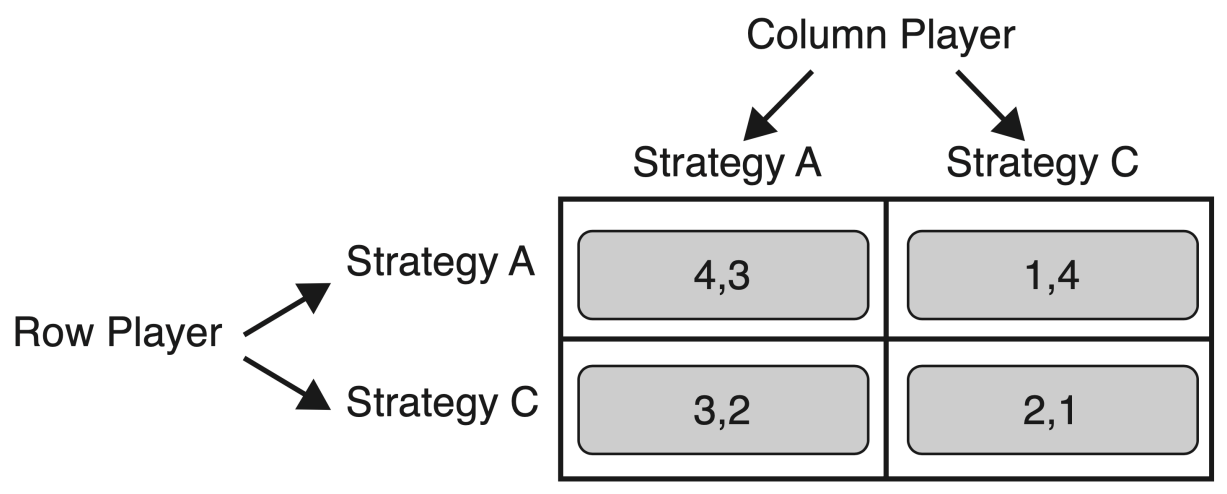

Figure 3. The preference matrix for the general power game. Higher numbers are preferred. The numbers to the left of the comma designate the preference of the Row player. Strategy A may be termed "accommodation"; strategy C may be termed "challenge." 
Once preferences have been identified, the theory of moves identifies each player's primary and secondary interest (Brams, 1994, 2011; Krueger, 2020). The primary interest is given by a strategy, either one's own or the opponent's, that yields consistently better results than its alternative. The secondary interest is a player's contingency plan. How will they respond once the opponent has shown their hand? In the power game, row is primarily interested in having an accommodating partner (if column chooses strategy A, row realizes either 4 or 3 points). Row's contingency plan is to play tit for tat. If column accommodates, row will too $(4>3)$; if column challenges, so will row $(2>1)$. Column's primary interest is also to have an accommodating partner, which yields 3 or 4 points. Column's contingency plan is to anti-reciprocate; if row accommodates, column's best response is to challenge; if row challenges, column will accommodate.

Both players have cause to be sensitive to their expectations regarding the other's move (Pruitt \& Kimmel, 1977) — and they are (Boone et al., 2008; Pletzer et al., 2018). Game-theoretically rational players (Luce \& Raiffa, 1957) are indifferent between strategies if the probability of the other player being accommodating is $\frac{\mathrm{P}-\mathrm{S}}{\mathrm{R}-\mathrm{S}-\mathrm{T}+\mathrm{P}}$, where $\mathrm{R}$ is the payoff for mutual accommodation, $\mathrm{T}$ denotes unilateral challenge, $\mathrm{P}$ mutual challenge, and $\mathrm{S}$ unilateral accommodation (Rapoport, 1967). With the presented payoff matrix, both players are indifferent when $\mathrm{p}($ Strategy $\mathrm{A})=.5$. However, if the other player's $\mathrm{p}>.5$, row favors accommodation, whereas column prefers to challenge. This asymmetry reflects the misalignment of the players' secondary interests. Both players may also ask how probable it is that the other player chooses the same strategy they themselves choose (Krueger, 2013). This probability, which reflects social projec- 
tion, leaves players indifferent if it is $\frac{T-S}{R-S+T-P}$. Here, the two players' outlooks are aligned. The more they project to the other, the more they gravitate to the mutually rewarding outcome of shared accommodation. In this way, the power game is similar to the prisoner's dilemma.

When presenting students $(\mathrm{N}=373)$ with the power game, we found that assuming the role of the row player, $47.7 \%$ preferred accommodation, whereas $75.5 \%$ wished to accommodate when in the role of the column player. This difference was significant (by McNemar's test), amounting to an odds ratio of 2.89. Figure 11.4 shows the distribution of joint frequencies for random pairing. The numbers in brackets show the coincidences when players are paired with their own preferences. The similarities between the random and the et ipsum pairings show that participants would not do better when playing against themselves.

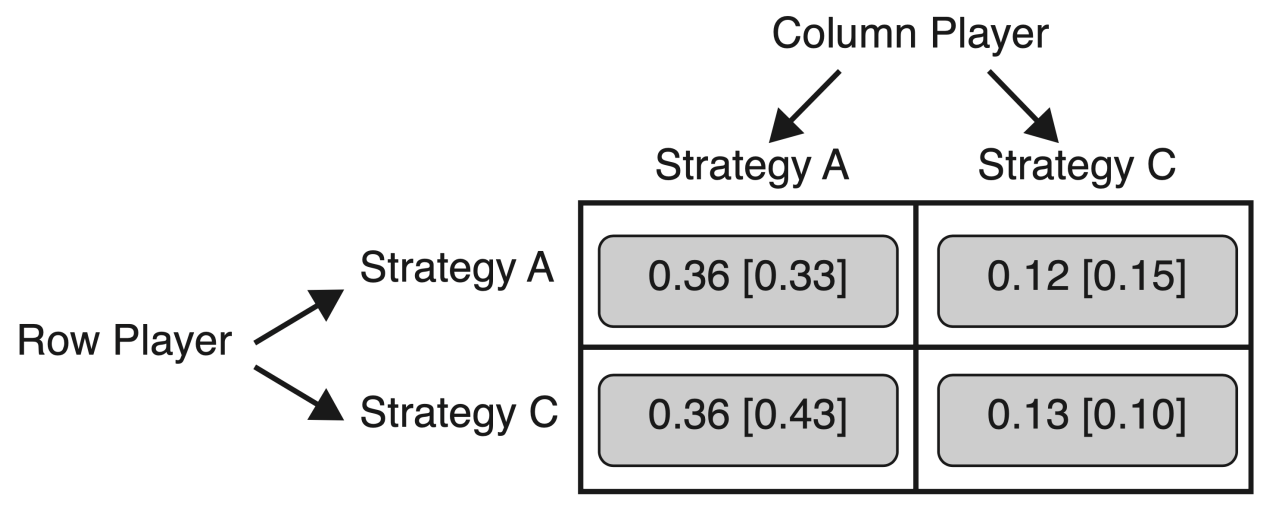

Figure 4. Coincidence matrix as estimated from student preferences in either role.

With a slight plurality finding themselves in the situation of a challenging row and an accommodating column, respondents failed to take full advantage of the efficient outcome of mutual accommodation. Interestingly, the probabilities of the pairings were more highly correlated with row's $(r=.87)$ than with column's payoffs $(r=.05)$ as though respondents implicitly identified with row. Indeed, row's expected value is greater (2.99) than column's (2.47) because col- 
umn accommodates above the Nash equilibrium. Figure 11.5 shows the expected values for the four possible outcomes as the product of the sum of the two payoffs times the [unbracketed] probability estimates shown in Figure 11.4. The sum of these four values, namely 5.46, represents the expected value of the entire game. This result is slightly better than the value obtained with Nash equilibrium play, that is, with each player selecting a strategy at random.

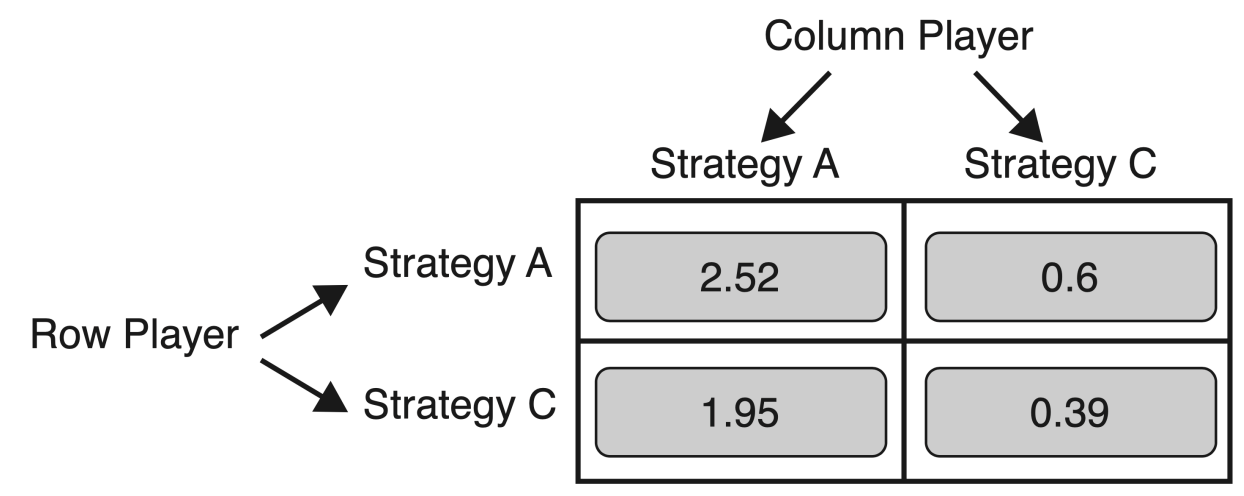

Figure 5. Estimated expected values for the general power game.

Why did respondents fail to play efficiently? Why did not more row players choose accommodation? Loss aversion might play a role (Tversky \& Kahneman, 1991). An accommodating row runs the risk of being suckered by a challenging column, whereas column's greatest fear is a counterchallenge from row. Despite the apparent advantages for row, respondents did not perceive a strong power differential between row $(M=4.16)$ and column $(M=4.00), d=.09$, on 7-point scales. They did, however, consider row $(\mathrm{M}=4.13)$ to be happier than column $(\mathrm{M}=$ $3.74), d=.24$. Judgments of happiness, it seems, were more sensitive to the likely outcomes, which favored row, whereas judgments of power reflected the ability to bring these outcomes about. Here, row had no advantage as there was no power of coercion. The dissociation between power and happiness also emerged in the low correlations between the two sets of ratings, which were .29 for row and .28 for column. 
As in the ultimatum game, we assessed perceptions of morality and competence with ratings on six trait-descriptive adjectives. We limited this investigation to perceptions given row's accommodation. Again, the two short scales had adequate internal consistency (all $\alpha>.77$ ). Correlations between morality and competence ranged from .26 to .57 . That is, the two dimensions of judgments were discriminable but seemed to share an evaluative core. When the players achieved mutual accommodation, row was seen as less moral $(\mathrm{M}=4.48)$ than column $(\mathrm{M}=$ $5.10), d=.49$. Respondents seemed to recognize column's sacrifice of foregoing a challenge, which would have returned a better value. There was no difference in perceived competence (M $=4.93$ and 4.82 , respectively, for row and column), $\mathrm{d}=.07$. When column challenged and row accommodated, perceptions markedly diverged. Now, column was seen not only as far less moral $(M=3.25)$ than row $(M=4.34), d=.58$ but also as more competent $(M=4.77$ versus 3.77$), d=$ .55. Under these circumstances, perceptions of morality and competence diverge in a way that highlights the column player's social dilemma. Challenging an opponent is a tough stance, analogous to defection in the prisoner's dilemma, and observers view defection as smart but mean (Krueger et al., 2020). Whether this logic extends to the row player remains to be seen in future studies including perceptions of row in the role of the challenger.

\section{Thinking, Shallow and Deep}

The power game, more so than the ultimatum game, requires players to ask how far ahead they are willing and able to think. Whereas in the ultimatum game, only the proposer needs to anticipate the responder's move, in the power game, both players stand to gain from correctly predicting the other's move. This prediction, in turn, requires a prediction of the other's prediction of one's own move. Once triggered, recursive predictions descend into a bottomless 
rabbit hole (Grüning \& Krueger, 2021; Stahl \& Wilson, 1995). Game theory solves this problem by finding the probabilistic Nash equilibrium (Nash, 1950). The rabbit hole's infinite regress leaves a random choice as rationality's last resort. As we have seen, however, this equilibrium is inefficient, and on average, our participants did a little better due to the column player's willingness to accommodate.

It seems unlikely that the difference between row and column player's willingness to accommodate is due to the same participants thinking more deeply and further ahead when taking the role of the column player than when taking the role of the row player. Recursive mentalizing is hard, and people tend to give up fast (Burchardi \& Penczynski, 2014). Yet, most think they have looked more deeply into the hole than others (Grüning \& Krueger, 2021). When they do, they express self-enhancement. As it stands, the data are most compatible with the view that participants used a loss-aversion heuristic in both roles.

\section{Can Social Value Orientations Resolve the Social Dilemma?}

It is reasonable to think that social preferences affect behavior in the power-sociability dilemma. We may ask how much individuals care about the payoffs accruing to others or about the differences between their own and others' payoffs (Messick \& McClintock, 1968). That is, we can ask if the values of benevolence or fairness (i.e., inequality aversion) affect social decision-making to tilt the balance away from power and toward sociability. We now revisit the ultimatum and the power game in light of van Lange's (1999) social value model. The model assigns a weight of 1 to a person's own payoffs and scales the weights apportioned to benevolence (w1) and fairness (w2) relative to the person's self-interest, with 0 and 1 bounding the theoretically and empirically likely range. Applying these values, a person transforms the objective payoffs 
into subjective payoffs. The subjective payoff for a unilateral competitive move, for example, is $\mathrm{T}^{\prime}=\mathrm{T}+\mathrm{w} 1 \mathrm{~S}-(\mathrm{w} 2|\mathrm{~T}-\mathrm{S}|)$. This value transformation, rooted in Thibaut and Kelley's (1959/2017) early work on interdependence, is linear. It is not assumed, in contrast to social preference models prevalent in economics, that payoffs are psychologically represented as concave utility functions (Fehr \& Schmidt, 1999). Also, unlike behavioral economic models, the social value model does not differentiate between favorable (guilt) and unfavorable inequality (envy).

In the ultimatum game, a benevolent player, who places a positive weight on the other's payoff $(\mathrm{w} 1>0)$ but no weight on the inequality of outcomes (w2 $=0)$, is at best indifferent to making or receiving different offers. For any w $1<1$, proposers prefer to offer less, while responders prefer to be offered more. Proposers who care about fairness will prefer an even split if w2 $>.5$, otherwise make a minimal offer (see Krueger et al., 2008, for a mathematical proof that the social value model cannot account for intermediate levels of cooperation; the model predicts all-or-nothing decisions). Responders who care about fairness are indifferent between accepting and rejecting an offer if $\mathrm{W}_{2}>\frac{\mathrm{R}}{10-2 \mathrm{R}}$, where 10 is the total available and $\mathrm{R}$ is the offer.

For the power game, a benevolence weight of 1 turns accommodation into a weakly dominating strategy for each player. Anything less preserves the structure of the game as given by the objective payoffs. As to the value of fairness, the row player would not perceive accommodation as the weakly dominating strategy unless w $2<-.5$, that is, unless the row player values unfairness. In contrast, accommodation weakly dominates for the column player if w $2>.5$, which lies within reach. This is an interesting result as it shows that in the asymmetric power game, social 
values can affect choices in different ways. Following convention, we have assumed that a social dilemma is mitigated inasmuch as cooperation increases and outcomes become more efficient. From this perspective, mitigation comes at the expense of the need for power. We now return to the question of how the dilemma may play out if both needs, power and sociability, are accepted as part of the natural human endowment.

\section{Reputational Concerns Amplify the Social Dilemma}

The ultimatum game and the power game pit people (players) against others whose choices can only be guessed; and they invite a concern about their own reputation. The social animal cares about what others think, be they real observers or a set of internalized standards. Yet reputations staked on power and sociability pull in opposite directions. Consider again a responder who rejects a 9:1 ultimatum and a column player in the power game who responds to row's accommodation with a challenge. The ultimatum rejector faces a choice between a comparatively small material gain and a large reputational gain along both moral and competent lines. Many individuals in this situation opt for the reputational gain, but then turn to their material interests when the stakes increase (Andersen et al., 2011). The challenger in the power game, however, sacrifices the morality bonus for the material gain and the reputation of competence.

The power-sociability dilemma is a fascinating, and perhaps tragic, fact of life. Human beings have much at stake: material interests and security, competitive advantage, interpersonal connectedness, cooperation, respect, and love. Some of this is just in a person's head in the form of a pleasing self-image or a favorable self-assessment—which can be inaccurate. As we have seen, social decisions are affected by these concerns in complex and, at times, surprising ways. The basic dilemma can be nudged and navigated, but it cannot be nullified. If sociability were 
the only concern, equality might be attained, as in the ultimatum game, or not, as in the power game. But any society of sociable saints is vulnerable to invasion by self-seeking exploiters, those who relish power for their own sake, or those who degrade the common good out of spite (Fowler, 2005), as did Achilles. Moreover, what seems to pass as a moral stance can be destructive. In both our sample games, the conventionally admired value of equality can precipitate states in which everyone is worse off.

Caring about what others think is often lauded as the socially responsible attitude (Mayeroff, 1965), but it hardly passes the bar to become a moral imperative. Brazilian author Joaquím Machado de Assis (1881/2020) satirized obeisance to public opinion when having his hero Brás Cubas declare that one "merely needs to consider the salutary effects of public opinion in order to conclude that it is the very finest achievement of the flower of mankind, that is, of the greater number” (p. 186). In psychology, clinical mastermind Albert Ellis (1962/2010) was among the first to claim that an inflated concern with reflected appraisals is a hallmark of neurosis (see also Brinkmann, 2019).

\section{The Incredibly Enduring Social Dilemma}

If reputational concerns fuel the social dilemma, so do the messages pervading contemporary culture. On the one hand, there are the moral mandates of cooperation, social mindfulness, and empathic concern that saturate familial, ecclesiastical, educational, and political narratives. The social institutions of family, church, school, and government have an interest in making us fit for society by making us fit in. A rocked boat is a danger to all, and so we are told not to rock it (Cialdini \& Goldstein, 2004). On the other hand, there are the siren songs of individual achievement, self-actualization, and power, which, we are told, characterize the excellent person. 
Many institutions contribute to the excellence-and-power narrative, but the personal coaching industry—taking its inspiration from Maslow (1954)—casts the message in its purest form. Two examples shall make the point. One example comes from the irrepressible Tony Robbins, who helps his clients to "Ignite. Achieve. Excel" (www.tonyrobbins.com). This is hard to do on one's own, so Robbins announces that he will make you "Skyrocket to success with a coach." Does it work? The testimonials say it does. Writes one "I feel on top of the word. I feel incredible, I feel motivated, I feel empowered. I am the master of my destiny." The power motive is a greedy master. Another example comes from the start-up company "BetterUp" (www.betterup.com), known for its employment of the Duke of Sussex as its Chief Impact Officer. Better.up describes its mission as to "unlock greater potential, purpose, and passion" (www.betterup.com/en-us/about-us). This narrative is seductive because it suggests that each client harbors inner greatness. It just needs to be "unlocked." This message tickles the power motive.

\section{From Conflict to Freedom}

A solution to the social dilemma, however fragile, requires a balance of the dual instincts to be sociable and to be powerful. A strong need of power can threaten group cohesion. The Ju'/ hoansi Bushmen of Southern Africa, for example, demand that successful hunters share their bounty, and they mock them even when they do (Suzman, 2021). In more hierarchal societies, some leaders succeed by cultivating a generous attitude toward others on their own accord (Zenger \& Folkman, 2020). Meanwhile, less dominant individuals can also gain favor and influence by projecting their own likability and sociability, a strategy found among chimpanzees as well (Newton-Fisher, 2004; Sandel et al., 2020). 
The inverse challenge arises when the need of sociability becomes too strong. Individuals who habitually seek acceptance, inclusion, and connection readily appease, cooperate, and conform, often to their own psychological and material detriment. These individuals need to find the courage to rebel (Gino, 2019) and assert themselves by cultivating a sense of what might be called "controlled eccentricity" (Krueger, 2019). The maintenance of a balance of power and sociability requires costly self-regulation. The person who achieves it may be said to be free. Freedom is a delicate achievement. It requires wisdom and work, and perhaps a passing familiarity with the relevant research literature.

\section{Acknowledgments}

We thank Forgas Joseph and Hume David for the inspiration they have given in spoken and written words, respectively. 


\section{References}

Alicke, M. D., Dunning, D. A., \& Krueger, J. I. (2005). The self in social judgment. New York: Psychology Press.

Alicke, M. D., \& Govorun, O. (2005). The better-than-average effect. In M. D. Alicke, D. A. Dunning, \& J. I. Krueger (Eds.), The self in social judgment (pp. 85-106). New York: Psychology Press.

Allport, F. H. (1924). Social psychology. Boston: Houghton Mifflin.

Andersen, S., Ertaç, S., Gneezy, U., Hoffman, M., \& List, J. A. (2011). Stakes matter in ultimatum games. American Economic Review, 101(7), 3427-3439. https://www.jstor.org/stable/41408744

Anderson, C., Hildreth, J. A. D., \& Howland, L. (2015). Is the desire for status a fundamental human motive? A review of the empirical literature. Psychological Bulletin, 141(3), 574601. https://doi.org/10.1037/a0038781

Baron, J., \& Hershey, J. C. (1988). Outcome bias in decision evaluation. Journal of Personality and Social Psychology, 54(4), 569-579. Https://doi.org/10.1037//0022-3514.54.4.569

Boone, C., Declerck, C. H., \& Suetens, S. (2008). Subtle social cues, explicit incentives and cooperation in social dilemmas. Evolution and Human Behavior, 29(3), 179-188. https:// doi.org/10.1016/j.evolhumbehav.2007.12.005

Brams, S. J. (1994). Theory of moves. Cambridge: Cambridge University Press.

Brams, S. J. (2011). Game theory and the humanities. Cambridge: MIT Press. 
Brown, J. D. (2012). Understanding the better than average effect: Motives (still) matter. Personality and Social Psychology Bulletin, 38(2), 209-219. https://doi.org/ $10.1177 / 0146167211432763$

Brinkmann, S. (2019). They joy of missing out: The art of self-restraint in an age of excess. Medford: Polity.

Burchardi, K. B., \& Penczynski, S. P. (2014). Out of your mind: Eliciting individual reasoning in one shot games. Games and Economic Behavior, 84, 39-57. https://doi.org/10.1016/ j.geb.2013.12.005

Byrne, D. (1961). Interpersonal attraction and attitude similarity. The Journal of Abnormal and Social Psychology, 62(3), 713-715. https://doi.org/10.1037/h0044721

Camerer, C. (2003). Behavioral game theory. Princeton: Princeton University Press.

Cheek, J. M., \& Buss, A. H. (1981). Shyness and sociability. Journal of Personality and Social Psychology, 41(2), 330-339. https://doi.org/10.1037/0022-3514.41.2.330

Christie, R., \& Geis, F. L. (1970). Studies in Machiavellianism. New York/San Francisco/London: Academic Press.

Cialdini, R. B., \& Goldstein, N. J. (2004). Social influence: Compliance and conformity. Annual Review of Psychology, 55, 591-622. https://doi.org/10.1146/ annurev.psych.55.090902.142015

Clement, R. W., \& Krueger, J. (1998). Liking persons versus liking groups: A dual-process hypothesis. European Journal of Social Psychology, 28(3), 457-469. https://doi.org/ 10.1002/(SICI)1099-0992(199805/06)28:3<457::AID-EJSP880>3.0.CO;2-T 
Codol, J.-P. (1975). On the so-called "superior conformity of the self" behavior: Twenty experimental investigations. European Journal of Social Psychology, 5(4), 457-501. https:// doi.org/10.1002/ejsp.2420050404

Ellis, A. (1962/2010). Overcoming destructive beliefs, feelings, and behaviors: New directions for rational emotive behavior therapy. Amherst: Prometheus Books.

Fehr, E., \& Schmidt, K. M. (1999). A theory of fairness, competition, and cooperation. Quarterly Journal of Economics, 114(3), 817-868. https://doi.org/10.1162/003355399556151

Fowler, J. H. (2005). Altruistic punishment and the origin of cooperation. Proceedings of the National Academy of Sciences, 102(19), 7047-7049. https://doi.org/10.1073/ pnas.0500938102

Gabay, A. S., Radua, J., Kempton, M. J., \& Mehta, M. A. (2014). The Ultimatum game and the brain: A meta-analysis of neuroimaging studies. Neuroscience \& Biobehavioral Reviews, 47, 549-558. https://doi.org/10.1016/j.neubiorev.2014.10.014

Gino, F. (2019). Rebel talent. London: Pan books.

Grüning, D. J., \& Krueger, J. I. (2021). Strategic thinking: A random walk into the rabbit hole. Collabra: Psychology, 7(1), 24921. https://doi.org/10.1525/collabra.24921

Gumplowicz, L. (1885/2017). Grundriss der Soziologie. Norderstedt: Hansebooks.

Güth, W., Schmittberger, R., \& Schwarze, B. (1982). An experimental analysis of ultimatum bargaining. Journal of Economic Behavior and Organization, 3(4), 367-388. https://doi.org/ $10.1016 / 0167-2681(82) 90011-7$

Heck, P. R., \& Krueger, J. I. (2015). Self-enhancement diminished. Journal of Experimental Psychology: General, 144(5), 1003-1020. https://doi.org/10.1037/xge0000105 
Heck, P. R., \& Krueger, J. I. (2016). Social perception of self-enhancement bias and error. Social Psychology, 47(6), 327-339. https://doi.org/10.1027/1864-9335/a000287

Heck, P. R., \& Krueger, J. I. (2020). Self-enhancement error motivates social projection. Social Cognition, 38(5), 489-522. https://doi.org/10.1521/soco.2020.38.5.489

Hume, D. (1740/1978). A treatise of human nature. Oxford: Oxford University Press.

Kamas, L., \& Preston, A. (2012). The importance of being confident; gender, career choice, and willingness to compete. Journal of Economic Behavior \& Organization, 83(1), 82-97. https://doi.org/10.1016/j.jebo.2011.06.013

Kazantzakis, N. (1946/2016). Zorba the greek. London: Faber \& Faber.

Keltner, D., Gruenfeld, D. H, \& Anderson, C. (2003). Power, approach, and inhibition. Psychological Review, 110, 265-284.

Krueger, J. I. (2000). The projective perception of the social world: A building block of social comparison processes. In J. Suls \& L. Wheeler (Eds.), Handbook of social comparison: Theory and research (pp. 323-351). New York: Plenum/Kluwer.

Krueger, J. I. (2002). On the reduction of self-other asymmetries: Benefits, pitfalls, and other correlates of social projection. Psychologica Belgica, 42, 23-41.

Krueger, J. I. (2007). From social projection to social behaviour. European Review of Social Psychology, 18(1), 1-35. https://doi.org/10.1080/10463280701284645

Krueger, J. I. (2011). Altruism gone mad. In B. Oakley, A. Knafo, G. Madhavan, \& D. S. Wilson (Eds.), Pathological altruism (pp. 392-402). Oxford: Oxford University Press.

Krueger, J. I. (2013). Social projection as a source of cooperation. Current Directions in Psychological Science, 22(4), 289-294. https://doi.org/10.1177/0963721413481352 
Krueger, J. I. (2014a). How Robinson Crusoe managed his Man Friday. Retrieved January 1, 2021, from www.psychologytoday.com/us/blog/one-among-many/201402/how-robinsoncrusoe-managed-his-man-friday

Krueger, J. I. (2014b). A general power game. Retrieved January 1, 2021, from www.psychologytoday.com/us/blog/one-among-many/201402/general-power-game

Krueger, J. I. (2019). Controlled eccentricity. Review of 'Rebel talent: Why it pays to break the rules at work and in life' by Francesca Gino. American Journal of Psychology, 132(3), 392-395. https://doi.org/10.5406/amerjpsyc.132.3.0392

Krueger, J. I. (2020). Prediction and explanation in a postmodern world. Frontiers in Psychology: Theoretical and Philosophical Psychology, 11, 597706. https://doi.org/10.3389/ fpsyg.2020.597706

Krueger, J. I., DiDonato, T. E., \& Freestone, D. (2012). Social projection can solve social dilemmas. Psychological Inquiry, 23(1), 1-27. https://doi.org/ 10.1080/1047840X.2012.641167

Krueger, J. I., Freestone, D., \& MacInnis, M. L. (2013). Comparisons in research and reasoning: Toward an integrative theory of social induction. New Ideas in Psychology, 31(2), 73-86. https://doi.org/10.1016/j.newideapsych.2012.11.002

Krueger, J. I., \& Funder, D. C. (2004). Towards a balanced social psychology: Causes, consequences, and cures for the problem-seeking approach to social behavior and cognition. Behavioral and Brain Sciences, 27(3), 313-327. https://doi.org/10.1017/ S0140525X04000081 
Krueger, J. I., \& Grüning, D. J. (2021). Psychological perversities and populism. In J. P. Forgas, J. P., Crano, W. D., \& Fiedler, K. (Eds.), The social psychology of populism. The 22nd Sydney symposium on social psychology (Vol. 23, pp. 125-142). New York: Routledge.

Krueger, J. I., Heck, P. R., \& Asendorpf, J. B. (2017). Self-enhancement: Conceptualization and assessment. Collabra: Psychology, 3(1), 28. www.collabra.org/article/10.1525/ collabra.91/

Krueger, J. I., Heck, P. R., Evans, A. M., \& DiDonato, T. E. (2020). Social game theory: Preferences, perceptions, and choices. European Review of Social Psychology, 31(1), 322-353. https://doi.org/10.1080/10463283.2020.1778249

Krueger, J. I., Ullrich, J., \& Chen, L. J. (2016). Expectations and decisions in the Volunteer's Dilemma: Effects of social distance and social projection. Frontiers in Psychology, 7, 1909. https://doi.org/10.3389/fpsyg.2016.01909

Krueger, J. I., Vogrincic-Haselbacher, C., \& Evans, A. M. (2019). Towards a credible theory of gullibility. In J. P. Forgas \& R. Baumeister (Eds.), The social psychology of gullibility: Conspiracy theories, fake news and irrational beliefs (pp. 103-122). Routledge.

Krueger, J. I., Vohs, K. D., \& Baumeister, R. F. (2008). Is the allure of self-esteem a mirage after all? American Psychologist, 63(1), 64-65. https://doi.org/10.1037/0003-066X.63.1.64

Larney, A., Rotella, A., \& Barclay, P. (2019). Stake size effects in ultimatum game and dictator game offers: A meta-analysis. Organizational Behavior and Human Decision Processes, $151,61-72$.

Larrick, R. P., Burson, K. A., \& Soll, J. B. (2007). Social comparison and confidence: When thinking you're better than average predicts overconfidence (and when it does not). Or- 
ganizational Behavior and Human Decision Processes, 102(1), 76-94. https://doi.org/ 10.1016/j.obhdp.2006.10.002

Lifschitz, A. (Ed.). (2021). Frederick the Great's philosophical writings. Princeton: Princeton University Press.

Lucas, R. E., Diener, E., Grob, A., Suh, M. E., \& Shao, L. (2000). Cross-cultural evidence for the fundamental features of extraversion. Journal of Personality and Social Psychology, 79(3), 1039-1056. https://doi.org/10.1037/0022-3514.79.3.452

Luce, R. D., \& Raiffa, H. (1957). Games and decisions: Introduction and critical survey. New York: Wiley.

Machado de Assis, J. M. (1881/2020). Posthumous memoirs of Brás Cuba (M. J. Costa \& R. Patterson, trans.). New York: Penguin.

Maslow, A. H. (1954). Motivation and personality. New York/Evanston/London: Harper \& Row. Mayeroff, M. (1965). On caring. International Philosophical Quarterly, 5(3), 462-474. https:// doi.org/10.5840/ipq1965539

McCrae, R. R., \& Costa, P. T., Jr. (1987). Validation of a five-factor model of personality across instruments and observers. Journal of Personality and Social Psychology, 52(1), 81-90. https://doi.org/10.1037/0022-3514.52.1.81

Messick, D. M., \& McClintock, C. G. (1968). Motivational bases of choice in experimental games. Journal of Experimental Social Psychology, 4(1), 1-25. https://doi.org/ $10.1016 / 0022-1031(68) 90046-2$

Mitchell, S. (2011). The iliad—Homer. New York: Atria. 
Moore, D. A. (2020). Perfectly confident: How to calibrate your decisions wisely. New York: Harper Collins.

Nash Jr, J. F. (1950). The bargaining problem. Econometrica: Journal of the Econometric Society, $18,155-162$.

Newton-Fisher, N. E. (2004). Hierarchy and social status in Budongo chimpanzees. Primates, 45, 81-87. https://doi.org/10.1007/s10329-003-0064-6

Pletzer, J. L., Balliet, D., Joireman, J., Kuhlman, D. M., Voelpel, S. C., \& van Lange, P. A. M. (2018). Social value orientation, expectations, and cooperation in social dilemmas: A meta-analysis. European Journal of Personality, 32(1), 62-83. https://doi.org/10.1002/ per.2139

Pruitt, D. G., \& Kimmel, M. J. (1977). Twenty years of experimental gaming: Critique, synthesis, and suggestions for the future. Annual Review of Psychology, 28, 363-392.

Rapoport, A. (1967). A note on the index of cooperation for prisoner's dilemma. Journal of Conflict Resolution, 11(1), 101-103. https://www.jstor.org/stable/172934

Rosler, A. (2013). Civic virtue: Citizenship, ostracism, and war, In M. Deslauriers \& P. Destrée (Eds.), The Cambridge companion to Aristotle's politics (pp. 144-175). Cambridge: Cambridge University Press.

Ross, L., Greene, D., \& House, P. (1977). The false consensus effect: An egocentric bias in social perception and attribution processes. Journal of Experimental Social Psychology, 13(3), 279-301. https://doi.org/10.1016/0022-1031(77)90049-X

Russell, B. (1938/2015). Power: A new social analysis. New York: Routledge. 
Sandel, A. A., Langergraber, K. E., \& Mitani, J. C. (2020). Adolescent male chimpanzees (Pan troglodytes) form social bonds with their brothers and others during the transition to adulthood. American Journal of Primatology, 82(1), e23091. https://doi.org/10.1002/ ajp.23091

Sapolsky, R. M. (2017). Behave: The biology of humans at our best and worst. New York: Penguin.

Schopenhauer, A. (1851/1964). The pessimist's handbook: A collection of popular essays. Lincoln: University of Nebraska Press.

Simmel, G. (1910/1949). The sociology of sociability. The American Journal of Sociology, 55(3), 254-261. https://www.jstor.org/stable/2771136

Stahl, D. O., \& Wilson, P. W. (1995). On players' models of other players: Theory and experimental evidence. Games and Economic Behavior, 10(1), 218-254. https://doi.org/ 10.1006/game.1995.1031

Suls, J., \& Wheeler, L. (2000). Handbook of social comparison: Theory and research. New York: Plenum/Kluwer.

Suzman, J. (2021). Work: A deep history, from the stone age to the age of robots. New York: Penguin.

Tarantola, T., Kumaran, D., Dayan, P., \& De Martino, B. (2017). Prior preferences beneficially influence social and non- social learning. Nature Communications, 8, 1-14.

Tham, Y. J., Hashimoto, T., \& Karasawa, K. (2021). The effect of impression formation on rejection in the ultimatum game. Letters on Evolutionary Behavioral Science, 12(1), 12-17. https://doi.org/10.5178/lebs.2021.83 
Thibaut, J. W., \& Kelley, H. H. (1959/2017). The social psychology of groups. New York: Routledge.

Thielmann, I., Hilbig, B. E., \& Zettler, I. (2018). Seeing me, seeing you: Testing competing accounts of assumed similarity in personality judgments. Journal of Personality and Social Psychology, 118(1), 172-198. https://doi.org/10.1037/pspp0000222

Tönnies F. (1887/2012) Gemeinschaft und Gesellschaft. In: Studien zu Gemeinschaft und Gesellschaft. Wiesbaden, VS Verlag für Sozialwissenschaften. https://doi.org/ 10.1007/978-3-531-94174-5_2.

Tversky, A., \& Kahneman, D. (1991). Loss aversion in riskless choice: A reference-dependent model. The Quarterly Journal of Economics, 106(4), 1039-1061. https://doi.org/ $10.2307 / 2937956$

Van Lange, P. A. M. (1999). The pursuit of joint outcomes and equality in outcomes: An integrative model of social value orientation. Journal of Personality and Social Psychology, 77(2), 337-349. https://doi.org/10.1037/0022-3514.77.2.337

Wilson, E. O. (2004). On human nature. Cambridge, MA: Harvard University Press.

Wu, J., Balliet, D., \& van Lange, P. A. M. (2016). Reputation, gossip, and human cooperation. Social and Personality Psychology Compass, 10(6), 350-364. https://doi.org/10.1111/ spc3.12255

Xiao, E., \& Houser, D. (2005). Emotion expression in human punishment behavior. Proceedings of the National Academy of Science, 102(20), 7398-7401. https://doi.org/10.1073/ pnas.0502399102 
Zenger, J. H., \& Folkman, J. R. (2020). A broader view of developing strengths. Leader to Leader, 95, 32-36. https://doi.org/10.1002/1t1.20480

i "Human beings find it profitable to live in communities, but their desires, unlike those of bees in a hive, remain largely individual; hence arises the difficulty of social life and the need of government” (Russell, 1938/2015, p. 165). 